\title{
Recovery of memory after reminder: Evidence for two forms of retrieval deficit induced by ECS
}

\author{
TERRY L. DeVIETTI and CRAIG E. BUC'Y \\ Central Washington State College, Ellensburg, Washington 98926
}

\begin{abstract}
Using a one-trial fear-conditioning paradigm and ECS, three experiments contrasted the generalization hypothesis with the dissociation/retrieval failure hypothesis in predicting the outcome of reminder treatment given to ECS subjects evidencing different degrees of amnesia at the time of treatment. Experiment I showed a small but reliable increase in retention when reminder was administered to ECS subjects showing strong amnesia. Experiment II showed virtually no effect of reminder when administered to ECS subjects showing partial amnesia. Experiment III provided evidence that the small amount of memory recovery obtained in Experiment I resulted from an interaction between memorial and confounding variables. With confounding variables controlled, reminder induced a very substantial recovery of memory in ECS subjects. These results are contrary to the generalization hypothesis but are consistent with the dissociation/retrieval failure hypothesis that ECS results in two forms of memory retrieval deficit which interact, under some conditions, to determine the degree of retention observed following reminder.
\end{abstract}

Historically, amnesia resulting from ECS administered after a training-trial footshock has been interpreted as evidence that memory-storage processes have been disrupted (Glickman, 1961; McGaugh, 1966; McGaugh \& Dawson, 1971). This view has been challenged by the finding that retention can be increased in ECS subjects by administering a memory jog (reminder) prior to the test (e.g., Koppenaal, Jagoda, \& Cruce, 1967; Lewis, Misanin, \& Miller, 1968; Miller \& Springer, 1972; Quartermain, McEwen, \& Azmitia, 1970). At first glance, this finding would seem to argue strongly that memory-retrieval processes rather than memory-storage processes have been disrupted by ECS. However, several aspects of the reminder data have led some to persist with the notion that ECS disrupts memory storage (Cherkin, 1972; Gold, Haycock, Macri, \& McGaugh, 1973; Haycock, Gold, Macri, \& McGaugh, 1973; Mah \& Albert, 1973). First, ECS seldom results in a complete retention deficit when compared to appropriate controls (e.g., Koppenaal et al, 1967; Pagano, Bush, Martin, \& Hunt, 1969). Second, reminder treatment, while increasing retention, often falls short of increasing retention to the same degree shown by subjects trained but not given ECS (e.g., Galluscio, 1971; Miller \& Springer, 1972). In the light of these observations, Cherkin (1972) has postulated that ECS, being a weak amnesic agent, allows some fraction of memory to be stored. Moreover, according to Cherkin, reminder serves as a weak training trial which generalizes to and summates with any memory surviving ECS. Thus, increased retention following reminder is viewed as

This research was supported in part by Grant GB-38790 from the National Science Foundation. Appreication is extended to Darlene A. Haynes for her aid in the collection of the data. Requests for reprints should be sent to Terry $L$. DeVietti, Department of Psychology, Central Washington State College, Ellensburg, Washington 98926. resulting from the summation of two weak memories rather than the release for behavioral expression of a formerly strong, although unretrievable, memory. It is clear from this generalization hypothesis that the degree of memory recovery resulting from reminder should be related to the amount of memory surviving amnesic treatment. There are data which tend to support this prediction (Cherkin, 1972; Gold et al, 1973; Haycock, et al, 1973). For example, Gold et al (1973) trained rats in a passive-avoidance paradigm and used direct stimulation of the cortex to produce amnesia. They reported that subjects showing complete amnesia, as defined by their initial test performance, did not show any evidence of memory recovery at a second test given after a reminder treatment. On the other hand, subjects displaying only partial amnesia, again defined by their initial test latencies, showed a strong reminder effect at the second test.

In a recent study with some apparent bearing on the generalization hypothesis, DeVietti, and Hopfer (1974a) varied the form of reminder treatment in independent groups of subjects $24 \mathrm{~h}$ before a test trial administered $120 \mathrm{~h}$ after training. The results appeared to be inconsistent with the generalization hypothesis, since a substantial, if not complete, recovery of memory was obtained in ECS subjects with reminder while a very strong amnesia was noted in ECS subjects receiving no reminder. However, in this experiment, subjects were not tested at the time of reminder treatment $(96 \mathrm{~h}$ after training). Recent data from our laboratory (unpublished) indicates that, under the conditions of the DeVietti and Hopfer study, ECS subjects show only a partial amnesia at $96 \mathrm{~h}$. Therefore, it is likely that, in the DeVietti and Hopfer experiment, reminder was presented to subjects only partially amnesic at the time of reminder treatment. With this consideration, perhaps 
the DeVietti and Hopfer study may be considered along with studies which tend to support the generalization hypothesis (Cherkin, 1972; Gold et al, 1973; Haycock et al, 1973).

Many investigators remain convinced that ECS disrupts memory retrieval processes (Lewis, 1969; Miller \& Springer, 1973; Nielson, 1968; Quartermain, McEwen, \& Azmitia, 1972). A recently advanced notion in this regard (DeVietti, Holliday, \& Larson, 1973), which can be called the dissociation/retrieval failure hypothesis, holds that ECS, following a training-trial footshock, results in two forms of memory retrieval deficit. In this view, one retrieval deficit appears as a relatively weak amnesia from which memory recovers spontaneously and may be likened to the memory deficit observed in dissociation of learning or state-dependency research (DeVietti \& Larson, 1971; Mayse \& DeVietti, 1971). The other retrieval deficit appears as a relatively permanent amnesia, yielding memory only to reminder (Lewis et al, 1968; Miller \& Springer, 1972; Quartermain et al, 1970). Some evidence from our laboratory suggests that these two forms of retrieval deficit interact to produce the degree of retention observed after training and ECS (DeVietti \& Hopfer, 1974b) or after training ECS and reminder (DeVietti \& Hopfer, 1974c).

Within a reminder paradigm, the present experiments attempted to contrast predictions of the generalization and dissociation/retrieval failure hypotheses. In order to obtain this objective we gave reminder at two test intervals which, in previous work (DeVietti \& Hopfer, 1974b) appeared to yield different degrees of amnesia following training and ECS.

\section{EXPERIMENT I}

This experiment tested the effects of reminder given to subjects $120 \mathrm{~h}$ after training and ECS. Amnesia appears to be very strong at this interval (DeVietti \& Hopfer, 1974a, b). Accordingly, the generalization hypothesis would predict that reminder, given at $120 \mathrm{~h}$, would have little or no influence upon a subsequent retention trial. On the other hand, the dissociation/retrieval failure hypothesis would predict a large increase in retention following reminder if no dissociation of learning interfered.

\section{Method}

Subjects and Apparatus. Subjects were 58 male Long-Evans rats from the Central Washington State Psychology animal colony and aged 90-120 days at the beginning of the experiment. The apparatus has been described in detail elsewhere (DeVietti \& Larson, 1971). Two identical chambers were used for fear conditioning and testing. They measured $20 \times 30 \mathrm{~cm}$ and were $30 \mathrm{~cm}$ high. The sides and top were Plexiglas while the back and front were aluminum painted flat gray. The grid floor was .64 -cm-diam stainless steel rods spaced $1.90, \mathrm{~cm}$ apart. A small hole just off center in the front wall allowed the insertion of a drinking tube with the orifice located approximately $5 \mathrm{~cm}$ into the chamber and $5 \mathrm{~cm}$ above the grid floor. A drinkometer circuit was formed between the water in the drinking tube and the grid floor. A $10-\mathrm{cm}$ loud speaker for delivery of the conditioned stimulus (15-sec, $1,200-\mathrm{Hz}, 90-\mathrm{dB}$ tone from a Heathkit tone generator) was positioned at floor level behind the rear wall of each chamber. Both chambers were individually enclosed in lighted fan-ventilated sound-attenuation boxes. A grid box, the noncontingent treatment chamber, had walls constructed entirely of Plexiglas ( $21 \times 56 \times 21 \mathrm{~cm}$ high) and was housed in a different room from the training-testing chambers. The diameter and spacing of the stainless steel floor rods of the noncontingent treatment chamber were identical to that of the training-testing chambers. Footshock, delivered through the grid floor of either the conditioning or noncontingent treatment chamber, was a $1.6-\mathrm{mA}$ scrambled shock $(3 \mathrm{sec}, 60 \mathrm{~Hz}, 330 \mathrm{~V}$ rms). Another grid box, the weak footshock chamber, measured $20 \times 23 \times 20 \mathrm{~cm}$ high and was constructed of Plexiglas with the front and rear wall of anodized aluminum. It was used to administer a weak $(0.6 \mathrm{~mA})$ scrambled footshock $(3 \mathrm{sec}, 60 \mathrm{~Hz}$, $124 \mathrm{~V} \mathrm{rms)} 121 \mathrm{~h}$ after training or noncontingent treatment. This apparatus was housed in yet another room. An ECS apparatus (Hayes, 1948) was set to deliver a 92-mA shock ( $200 \mathrm{msec}, 60 \mathrm{~Hz}, 1,840 \mathrm{~V} \mathrm{rms})$ to the ears of the rat through wire clips fashioned to interlock with baby clothes snaps (Prims No. 0) previously fitted to each ear.

Procedure. The subjects were fitted with ear snaps and then individually housed. Food and water were provided ad lib throughout the experiment, except that water was withheld $24 \mathrm{~h}$ prior to drink training and testing (see below). On the day following the start of individual housing, each rat was handled for $5 \mathrm{~min}$. During the next 4 days, the subjects were given experience with the various aspects of the experimental situation according to the following schedule. On the first day, each rat was placed into one of the two training-testing chambers and left there for $10 \mathrm{~min}$. During this interval, water was removed from the home cage. The following day, each rat was taken to the chamber, its nose was gently touched to the drinking tube now present, and it was then released near the rear of the chamber. After the subject had completed a total of $55 \mathrm{sec}$ of contact with the drinking tube, it was returned to its home cage where water was again available. On the 3 rd day, the subjects were fitted with the ECS leads, placed in the chambers for $1 \mathrm{~min}$, and the home-cage water was removed. The next day, the subjects were again allowed to complete $55 \mathrm{sec}$ of contact with the drinking tube. The drinking tube was present in the chambers only during the two drink training days described above and on the test days described below.

On Day 5, the subjects were randomly assigned to one of two treatment conditions. Subjects in one group (TFS/ECS) had the ECS leads attached and were placed separately into one of the two chambers. One minute later the 15 -sec tone was presented with footshock, delivered through the grid floor, occurring during the last $3 \mathrm{sec}$ of the tone. ECS followed $.5 \mathrm{sec}$ after offset of tone and footshock. Subjects in the other group (NCFS/ECS) were placed in the noncontingent treatment chamber and received footshock and ECS. Two additional subjects (TFS) were given tone and footshock only. These two subjects served to establish the effectiveness of the training procedure.

Approximately half the subjects in each group received reminder treatment consisting of a test trial and a weak footshock $120 \mathrm{~h}$ after training or noncontingent treatment. Specifically, testing consisted of gently touching the rat's nose to the drinking tube in the chamber and releasing it near the rear of the chamber. After the subject had completed $50 \mathrm{sec}$ of tube contact, the tone was automatically presented and remained on until the subject completed an additional $5 \mathrm{sec}$ of contact with the tube or until $600 \mathrm{sec}$ had elapsed since tone onset. The time (in seconds) for the subjects to complete $5 \mathrm{sec}$ of tube contact in 
Table 1

Mean Log Drink Latencies in Seconds ( \pm One Standard Error)

\begin{tabular}{|c|c|c|c|c|}
\hline Group & $\begin{array}{c}\text { TFS } / \mathrm{ECS}_{\mathrm{R}} \\
\mathrm{N}=15\end{array}$ & $\begin{array}{c}\text { NCFS/ECS } \\
\mathrm{N}=15\end{array}$ & $\begin{array}{l}\mathrm{TFS} / \mathrm{ECS}_{\mathrm{NR}} \\
\mathrm{N}=15\end{array}$ & $\begin{array}{c}\text { NCFS/ECS } \\
\mathrm{N}=13\end{array}$ \\
\hline $\begin{array}{l}\text { Test 1: } 120 \mathrm{~h} \text { after ECS } \\
\text { Test 2: } 147 \mathrm{~h} \text { after ECS }\end{array}$ & $\begin{array}{ll}1.59 & ( \pm .11) \\
1.99 & ( \pm .11)\end{array}$ & $\begin{array}{ll}1.41 & ( \pm .10) \\
1.28 & ( \pm .11)\end{array}$ & $1.55 \quad( \pm .11)$ & $1.60( \pm .11)$ \\
\hline
\end{tabular}

Note. $R=$ reminder,$N R=$ no reminder.

the presence of the tone was automatically recorded and served as data for analysis. One hour following testing, the subjects were given footshock in the weak footshock chamber. One-half hour later, water was made available in the home cage for $2 \mathrm{~h}$. These subjects were tested again, $24 \mathrm{~h}$ thirsty, the following day. This second test occurred approximately $147 \mathrm{~h}$ after training or noncontingent treatment. The remaining subjects served as controls for the reminder treatment. They were not tested at $120 \mathrm{~h}$ but had access to water in the home cage for $5 \mathrm{~min}$ scheduled so as to coincide with the test interval; neither did they receive weak footshock. However, these control subjects were maintained on the same water-deprivation schedule as the reminder groups and were tested for the first time $147 \mathrm{~h}$ after training or noncontingent treatment.

\section{Results}

The latencies to complete $5 \mathrm{sec}$ of contact with the drinking tube in the presence of the tone were transformed to logarithms and analyzed with two separate analyses of variance. A split-plot analysis evaluated the drink latencies of the TFS/ECS and NCFS/ECS groups at the first and second tests, i.e., before and after reminder. A completely randomized analysis evaluated the drink latencies of the TFS/ECS and NCFS/ECS groups given reminder with those not given reminder. These data were obtained $147 \mathrm{~h}$ after training or noncontingent treatment.

Training was effective, as shown by the long latencies of the two subjects given TFS alone $(\operatorname{logs} 2.65$ and 2.78 in the first test). These data are well within the range of TFS subjects' test performance obtained previously with these training parameters (DeVietti \& Hopfer, 1974b). Table 1 contains a summary of the latencies to drink in the presence of the tone for each group. The split-plot analysis revealed that, overall, TFS/ECS subjects showed retention relative to the NCFS/ECS controls $[F(1,28)=$ $13.12, \mathrm{p}<.01]$, and that retention did not differ between the first and second tests $[F(1,28)=2.09$, $\mathrm{p}>.05]$. However, as indicated by the reliable interaction between groups and tests $[F(1,28)=7.73$, $\mathrm{p}<.01$ ], reminder differentially influenced retention in the two groups. The analysis of the simple main effects of the interaction indicated a strong amnesia in TFS/ECS subjects, since their drink latencies did not differ from the NCFS/ECS controls at the first test $[F(1,56)=1.42, p>.05]$ but TFS/ECS subjects showed memory at the second test $[F(1,56)=20.73, p<.01]$ when compared with the controls. Evidence of memory recovery in TFS/ECS subjects was also obtained by evaluating drink performance between the first and second tests $[F(1,28)=8.90, p<.01]$. The increase in drink latencies at the second test by TFS/ECS animals, though of small magnitude, was impressive, since 14 of the 15 animals showed the effect. Reminder, if anything, influenced the controls in the reverse fashion. However, the decrease in drink latencies from the first to second tests was not reliable in this case $[\mathrm{F}(1,28)<1, \mathrm{p}>.05]$.

The correlation between drink latencies in the first and second tests for TFS/ECS animals given reminder was calculated to determine whether amount of initial retention was related to memory recovery. Only a very weak, direct relationship was obtained $[\mathrm{r}=.33$, $\mathrm{t}(13) \approx 1.33, \mathrm{p}>.20]$

The completely randomized analysis indicated that the reminder treatment rather than the time of test, resulted in the increased retention in TFS/ECS subjects at the second test. Overall, TFS/ECS subjects had longer drink latencies than NCFS/ECS controls $[F(1,54)=$ $9.01, p<.01]$ but no overall influence of reminder was determinable $[F(1,54)<1, p>.05]$. However, the interaction between reminder and groups was reliable $[F(1,54)=11.80, p<.01]$. The breakdown of the simple main effects revealed TFS/ECS subjects given reminder had longer drink latencies than either similarly treated NCFS/ECS subjects or TFS/ECS subjects not given reminder $[F(1,54)=20.68$ and 8.14 , respectively, ps $<.01]$. NCFS/ECS controls did not differ with respect to reminder treatment $[F(1,54)=3.98$, $p>.05]$. The difference between these latter two groups was in the opposite direction of increased retention by reminder animals.

\section{Discussion}

Reminder, administered to TFS/ECS subjects showing strong amnesia, produced a small but reliable increase in retention. This result might be considered as consistent with the generalization hypothesis since, even though the difference between TFS/ECS and NCFS/ECS subjects in the first test was not statistically reliable, it is theoretically impossible on both statistical and logical grounds to obtain a complete amnesia. However, in contradiction to this hypothesis, only a very small and nonsignificant relationship was found between the degree of initial amnesia and the degree of memory recovered. The results of the present experiment might also be predictable from the dissociation/retrieval failure 
Table 2

Mean Log Drink Latencies in Seconds ( \pm One Standard Error)

\begin{tabular}{|c|c|c|c|c|}
\hline Group & $\begin{array}{c}\text { TFS } / \text { ECS }_{\mathbf{R}} \\
\mathrm{N}=17\end{array}$ & $\begin{array}{c}\text { NCFS/ECS } \\
\mathrm{N}=17 \\
\end{array}$ & $\begin{array}{c}\text { TFS/ECS } \\
\mathrm{NR} \\
\mathrm{N}=17 \\
\end{array}$ & $\begin{array}{c}\text { NCFS/ECS } \\
\mathrm{NR} \\
\mathrm{N}=17\end{array}$ \\
\hline Test 1: $24 \mathrm{~h}$ after ECS & $2.00 \quad( \pm .09)$ & $1.56 \quad( \pm .13)$ & & \\
\hline Test 2: $51 \mathrm{~h}$ after ECS & $1.73( \pm .15)$ & $1.52( \pm .14)$ & $1.88( \pm .15)$ & $1.63( \pm .10)$ \\
\hline
\end{tabular}

Note $-R=$ reminder,$N R=$ no reminder .

hypothesis if dissociation induced by footshock and ECS was present at the time of reminder.

\section{EXPERIMENT II}

In this experiment, reminder was administered $24 \mathrm{~h}$ after TFS/ECS or NCFS/ECS. According to the generalization hypothesis, reminder should be more effective at this interval than at $120 \mathrm{~h}$ (Experiment I) since TFS/ECS subjects tested at this interval typically show only partial amnesia (DeVietti \& Hopfer, 1974c). On the other hand, the dissociation/retrieval failure hypothesis would hold that little or no effect of reminder should be observed with reminder administered $24 \mathrm{~h}$ after TFS/ECS. Previous work (DeVietti \& Larson, 1971; Mayse \& DeVietti, 1971) has indicated that footshock and ECS interact to produce a dissociation of learning lasting up to $72 \mathrm{~h}$ (DeVietti, Mayse, \& Morris, 1974). Thus TFS/ECS subjects should be in a brain state dissociated from that existing at acquisition when given reminder at $24 \mathrm{~h}$. Under these conditions, no effect of reminder would be expected.

\section{Method}

Subjects and Apparatus. Subjects were 68 male Long-Evans rats from the Central Washington State Psychology animal colony of the same age as in Experiment I. The apparatus was the same as described in Experiment $I$.

Procedure. Subjects were randomly assigned to receive either TFS/ECS or NCFS/ECS and were treated identically to those in Experiment I. Again, two additional subjects received only TFS. The sole difference between this experiment and Experiment I was that the initial test and weak footshock was given to half the subjects $24 \mathrm{~h}$ rather than $120 \mathrm{~h}$ after training or noncontingent treatment and these subjects were retested the following day (approximately $51 \mathrm{~h}$ after TFS/ECS or NCFS/ECS). The remaining subjects were neither tested initially nor given weak footshock but were tested $51 \mathrm{~h}$ after TFS/ECS or NCFS/ECS.

\section{Results}

Training was effective, since the two subjects given TFS alone showed long latencies, indicative of good retention, in the first test (logs 2.70 and 2.78). These data compare favorably to similarly treated subjects tested at $24 \mathrm{~h}$ (DeVietti \& Hopfer, 1974b).

Table 2 contains the data used in both the split-plot and completely randomized analyses of variance. The split-plot analysis of the two groups at each test indicated that, overall, TFS/ECS subjects had longer drink latencies than the NCFS/ECS controls $[F(1,32)=$ $5.12, \mathrm{p}<.05]$. However, retention did not differ between the two tests either overall $[\mathrm{F}(1,32)=1.62$, $\mathrm{p}>.05]$ or as a function of group $[\mathrm{F}(1,32)<1$, $p>.05]$. That a less complete amnesia was obtained in TFS/ECS subjects in the present experiment was demonstrated by the fact that their 24-h latencies were higher than TFS/ECS subjects tested in Experiment I at $120 \mathrm{~h}[\mathrm{t}(30)=2.94, \mathrm{p}<.01]$. Also, the 24-h drink latencies of the TFS/ECS group were higher than those of their NCFS/ECS controls [ $t(64)=2.34, p<.02]$, whereas this comparison failed to reveal a difference in Experiment I.

The completely randomized analysis of variance also failed to provide any support for the notion that reminder was effective in modifying drink latencies. Neither the main effects of groups, reminder, nor their interaction, approached statistical reliability $[\mathrm{F}(1,64)=$ $2.88,<1$ and $<1$, respectively ps $>.05$ ]

\section{Discussion}

Although a partial amnesia was demonstrated in ECS subjects, the same reminder treatment shown effective in Experiment I did not occasion greater retention in the present experiment. This finding is inconsistent with the generalization hypothesis. According to this notion, reminder should have resulted in greater retention in ECS subjects than was observed in Experiment I. In fact, reminder did not influence retention at all in the present experiment. This failure of reminder to influence recovery $24 \mathrm{~h}$ after TFS/ECS has been noted before in our laboratory under somewhat different reminder conditions (DeVietti \& Hopfer, 1974c), and this result clearly supports the dissociation aspect of the dissociation/retrieval failure hypothesis. In this view, reminder failed to release memory for behavioral expression because this treatment was administered to subjects with brain states modified by the training-trial footshock and ECS from the brain states existing at acquisition.

\section{EXPERIMENT III}

The small amount of retention induced by reminder at $120 \mathrm{~h}$ (Experiment I) could be viewed as reasonably consistent with either the generalization or the dissociation/retrieval failure hypothesis. However, 
Table 3

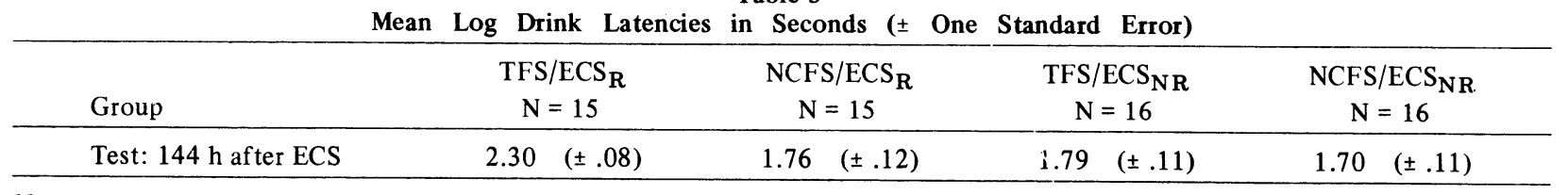

Note $-R=$ reminder,$N R=$ no reminder .

several aspects of the data suggested that other, less theoretical, factors may have modified the reminder effect. In both Experiments I and II, subjects were water-deprived for $24 \mathrm{~h}$ prior to testing where they received some water. In the case of controls, $5 \mathrm{~min}$ of water access was given in the home cage. All subjects were then given access to water in the home cage for $2 \mathrm{~h}$ and were again water-deprived for $24 \mathrm{~h}$ prior to the second test. Several aspects of the data from the second test suggested that subjects were more motivated to drink then than during the first test. For example, the four subjects given only TFS showed much shorter drink latencies at the second test, relative to the first, even though two had received reminder. Also, in Experiment I, TFS/ECS subjects not given reminder had lower latencies at the second test (approximately $147 \mathrm{~h}$ ) than TFS/ECS subjects at the first test $(120 \mathrm{~h})$. Under similar experimental conditions with subjects water-deprived for only one 24-h interval, we have observed the reverse trend (DeVietti \& Hopfer, 1974b). Finally, the latencies to complete an initial $50 \mathrm{sec}$ of tube contact before the presentation of the tone, routinely recorded in our studies, were lower in the second test for the TFS/ECS group given reminder at $120 \mathrm{~h}$. In our previous studies showing a reminder effect, we observed higher latencies both for initial drinking and for drinking in the presence of the tone (DeVietti \& Hopfer, 1974a, c). Some, but not all, of the present observations might be related to the varying durations of exposure to the drinking chamber and tone in the different treatment groups prior to weak footshock. The present experiment was designed to determine whether this factor and/or increased thirst could have produced the small amount of retention obtained by reminder at $120 \mathrm{~h}$ in Experiment $\mathrm{I}$.

\section{Method}

Subjects and Apparatus. Subjects were 64 male rats of the same age and history as used in Experiments I and II. The apparatus was identical to that described in the previous two experiments.

Procedure. Subjects were trained as in Experiments I and II. Half of them received TFS/ECS and the other half NCFS/ECS. Two additional subjects received only TFS. Approximately half of the subjects were given reminder $120 \mathrm{~h}$ following TFS/ECS or NCFS/ECS. Reminder consisted of automatic presentation of the tone for $15 \mathrm{sec}$ beginning $1 \mathrm{~min}$ after placement in the drinking chamber. One hour later, these subjects were again removed from the home cage and were given weak footshock.
They were not water deprived prior to reminder. The remaining subjects were neither exposed to the tone and drinking chamber nor given weak footshock. All subjects were tested, $24 \mathrm{~h}$ thirsty, the following day.

\section{Results}

As before, the two subjects given TFS showed relatively long test latencies (logs 2.50 and 2.69), indicating that training was effective.

Table 3 contains the drink latencies obtained in the presence of the tone for the TFS/ECS and NCFS/ECS groups. These data were analyzed by a completely randomized analysis of variance with groups and presence or absence of reminder serving as main effects. Overall, TFS/ECS subjects had longer drink latencies than NCFS/ECS subjects $[F(1,58)=8.43, p<.01]$ and subjects given reminder had longer drink latencies than subjects that were not $[F(1,58)=7.25, p<.01]$. The interaction between groups and reminder also reached statistical significance $[F(1,58)=4.29, p<.05]$. The breakdown of this interaction supported the impression gained by inspection of Table 3 that reminder very effectively increased drink latencies in TFS/ECS subjects. Under conditions of reminder, TFS/ECS subjects had longer drink latencies than NCFS/ECS controls $[F(1,58)=12.30, p<.01]$, whereas the two groups not given reminder did not differ $[F(1,58)<1$, $\mathrm{p}>.05]$. Further support for a reminder effect, unique to subjects trained and given ECS, was gained by the finding that TFS/ECS subjects given reminder had longer drink latencies than TFS/ECS subjects not given reminder $[F(1,58)=11.35, p<.01]$ whereas this comparison with the NCFS/ECS groups did not yield a difference $[F(1,58)<1, p>.05]$. Finally, TFS/ECS subjects given reminder in the present experiment showed longer drink latencies than similarly treated subjects, water deprived on 2 consecutive days prior to testing, in Experiment I [ $\mathrm{t}(28)=5.25, \mathrm{p}<.01]$.

\section{Discussion}

The results of this experiment strongly suggest that the small increase in drink latencies of the TFS/ECS group following reminder in Experiment I resulted from increased thirst and/or uncontrolled exposure to training cues prior to weak footshock in interaction with a strong reminder effect.

The very high degree of memory recovery displayed 
by TFS/ECS subjects given reminder in Experiment III (mean $\log 2.30$ ) is in good agreement with that displayed by ECS subjects given reminder at $96 \mathrm{~h}$ [mean logs 2.30 (DeVietti \& Hopfer, 1974c) and 2.33 (DeVietti \& Hopfer, 1974a)], an interval of little or no dissociation interference (DeVietti \& Larson, 1971; DeVietti et al, 1974; Mayse \& DeVietti, 1974). This finding of a high degree of memory recovery resulting from reminder treatment administered to subjects showing strong amnesia is consistent with the retrieval failure aspect of the dissociation/retrieval failure hypothesis.

\section{GENERAL DISCUSSION}

In the present experiments, the degree of amnesia displayed by ECS subjects prior to reminder was manipulated by varying the interval between training ECS and the reminder treatment. Reminder occasioned memory recovery when amnesia was strong and was without effect when amnesia was weak. These results are not consistent with the generalization hypothesis. In fact, they are directly contrary to expectations derived from this hypothesis, at least in its current stage of development.

On the other hand, these results would seem to be quite explainable in terms of the dissocation/retrieval failure hypothesis. Reminder was ineffective in restoring memory in TFS/ECS subjects when administered $24 \mathrm{~h}$ after the training-trial footshock and ECS (Experiment I). This result is consistent with earlier reports (DeVietti et al, 1973; DeVietti \& Larson, 1971; DeVietti et al, 1974; Mayse \& DeVietti, 1971) indicating that footshock and ECS result in a dissociation of learning measurable $24 \mathrm{~h}$ later.

In subjects shown to be strongly amnesic (Experiment I), reminder resulted in memory recovery. Moreover, with confounding variables controlled (Experiment III), the degree of memory recovery was very high and approached a level shown to be essentially complete in a previous report (DeVietti \& Hopfer, 1974a). This degree of recovery is consistent with the notion that reminder releases for behavioral expression a strong memory formerly suppressed by ECS rather than simply providing a weak training experience which summates with any remnant of memory surviving ECS.

One may wonder if controlling the confounding factors which apparently acted to keep the degree of memory recovered in Experiment I small, might also result in the finding of memory recovery when reminder is administered $24 \mathrm{~h}$ after TFS/ECS. Although no data addressed to this question are provided in the present report, a recent study (DeVietti \& Hopfer, 1974c) indicates that this possibility is unlikely. In that study, subjects were given TFS/ECS and a reminder treatment $24 \mathrm{~h}$ later. Reminder consisted of a 15-sec exposure to the conditioning tone and weak footshock $1 \mathrm{~h}$ later. The subjects were tested the following day after a single 24-h period of water deprivation. There was no evidence of memory recovery. Thus, it appears to be very difficult, under our conditions, to obtain a reminder effect $24 \mathrm{~h}$ after training and ECS. This finding is in conflict with many studies which have given reminder treatment $24 \mathrm{~h}$ after training and ECS and obtained memory recovery (e.g., Gold et al, 1973; Koppenaal et al, 1967; Lewis et al, 1968). Additionally, Miller and Springer (1972) provide data suggesting that the interval between training ECS and reminder treatment is of little consequence in obtaining memory recovery. The reasons for this discrepancy remain unknown but several obvious procedural differences exist. Most notable is our use of a conditioned fear paradigm whereas the majority of investigators have relied upon some type of passive-avoidance paradigm. Perhaps one task is more sensitive to certain effects of ECS than the other or, alternately, ECS disrupts different processes in the different tasks.

One further aspect of the data contained in the present report needs consideration. The fact that ECS subjects given reminder at $120 \mathrm{~h}$ in Experiment III showed a high degree of memory recovery might be considered as contrary to the dissociation aspect of the dissociation/retrieval failure hypothesis since dissociation appears to be present at this interval (DeVietti et al, 1974). Thus, interference with the reminder effect might be expected to be present here as well as at $24 \mathrm{~h}$ (Experiment II). Obviously, the results of Experiment III are contrary to that expectation. It may be that dissociation, to interfere effectively with reminder, must be present at the time of both reminder and testing. For example, previous research indicates that dissociation is present at both 24 and $48 \mathrm{~h}$ after footshock ECS (DeVietti et al, 1974), and effective interference has been obtained when reminder is given at $24 \mathrm{~h}$ with the test at $48 \mathrm{~h}$ both in Experiment II and elsewhere (DeVietti \& Hopfer, 1974c). On the other hand, dissociation is absent at 96 and $144 \mathrm{~h}$ after footshock ECS but present at $120 \mathrm{~h}$ (DeVietti et al, 1974). No interference has been obtained when reminder is given at $96 \mathrm{~h}$ with the test at $120 \mathrm{~h}$ (DeVietti \& Hopfer, 1974a, c), or when reminder is given at $120 \mathrm{~h}$ with the test at $144 \mathrm{~h}$ (Experiment III). Further research will be necessary to test the possibility that dissociation interference occurs only when a brain state dissociated from that during acquisition is present at both the reminder and test intervals.

Considering the results of the present three experiments, no apparent advantage is gained by invoking the notion that ECS disrupts memory storage as an explanation of the data. Rather, these results would seem to provide strong support for the notion that ECS interferes with two forms of memory retrieval which interact to determine the degree of retention 
observed following reminder.

\section{REFERENCES}

Cherkin, A. Retrograde amnesia in the chick: Resistance to the reminder effect. Physiology and Behavior, 1972, 8, 949-955.

DeVietti, T. L., Holliday, J. H., \& Larson, R. C. Comparison of amnesias induced by electroconvulsive shock administered after training-trial footshock or noncontingent footshock in rats. Journal of Comparative and Physiological Psychology, $1973,84,579-585$.

DeVietti, T. L., \& Hopfer, T. M. Complete amnesia induced by ECS and complete recovery of memory following reinstatement treatment. Physiology and Behavior, 1974a, 12 , 599-603.

DeVietti, $T_{n} L_{\circ}$, \& Hopfer, $T_{\text {, }} M_{\circ}$ ECS induced amnesia: Retention function consistent with state dependency predictions. Physiological Psychology, 1974b, 2, 35-37.

DeVietti, T. L., \& Hopfer, T M. Reinstatement of memory in rats: Dependence upon two forms of retrieval deficit following ECS. Journal of Comparative and Physiological Psychology, 1974c, 86, 1090-1099.

DeVietti, T. L., \& Larson, R. C. ECS effects: Evidence supporting state-dependent learning in rats. Journal of Comparative and physiological Psychology, 1971, 74, 407-415.

DeVietti, T. L., Mayse, J. F., \& Morris, L. W. Footshock/ECS induced state dependent learning in rats: Parametric evaluation of ECS intensity and time of testing. Learning and Motivation. 1974, 5, 70-79.

Galluscio, E. H. Retrograde amnesia induced by electroconvulsive shock and carbon dioxide anesthesia in rats: An attempt to stimulate recovery. Journal of Comparative and l'hy siological Psychology, 1971, 75, 136-140.

Glickman, S. E. Perseverative neural processes and consolidation of the memory trace. Psychological Bulletin, 1961, 58 218-233.

Gold, P. E., Haycock, J。 W., Macri, J., \& McGaugh, J. L. Retrograde amnesia and the "reminder effect": An alternative interpretation. Science, 1973, 180, 1199-1201.

Haycock, J. W., Gold, P. E., Macri, J., \& McGaugh, J. L. Noncontingent footshock attenuation of retrograde amnesia:
A generalization effect. Physiology and Behavior, 1973, 11, 99-102.

Hayes, K. J. Cognitive and emotional effects of electroconvulsive shock in rats. Journal of Comparative and Physiological Psychology, 1948, 41, 40-61.

Koppenaal, R. J. Jagoda, E., \& Cruce, J. A. F. Recovery from ECS-produced amnesia following a reminder. Psychonomic Science, 1967, 9, 293-294.

Lewis, D. J. Sources of experimental amnesia. Psychological Review, 1969, 76, 4ij1-472.

Lewis, D. J., Misanin, J. R., \& Miller, R. R. Recovery of memory following amnesia. Nature, 1968, 220, 704-705.

Mah, C. J., \& Albert, D. J. Electroconvulsive shock-induced retrograde amnesia: An analysis of the variation in the length of the amnesia gradient. Behavioral Biology, 1973, 9, 517-540.

Mayse, J. F., DeVietti, T. L. A comparison of state depentent learning induced by electroconvulsive shock and pentobarbital. Physiology and Behavior, 1971, 7, 717-721.

McGaugh, J. L. Time-dependent processes in memory storage. Science, 1966, 153, 1351-1358.

McGaugh, J. L., \& Dawson, R. G. Modification of memory storage processes. Behavioral Science, 1971, 16. 45-64.

Miller, R. R. \& Springer, A. D. Amnesia, consolidation and retrieval. Psychological Review, 1973, 80, 69-79.

Miller, R. R., \& Springer, A. D. Induced recovery of memory in rats following electroconvulsive shock. Physiology and Behavior, 1972, 8, 645-651.

Nielson, H. C. Evidence that electroconvulsive shock alters memory retrieval rather than memory consolidation. Experimental Neurology, 1968, 20, 3-20.

Pagano, R. R., Bush, D. F., Martin, G., \& Hunt, E. B. Duration of retrograde amnesia as a function of electroconvulsive shock intensity. Physiology and Behavior, 1969, 4, 98-105.

Quartermain, D., McEwen, B. S., \& Azmitia, E. C., Jr. Amnesia produced by electroconvulsive shock or cycloheximide: Conditions for recovery. Science, 1970, 169, 683-686.

Quartermain, D., McEwen, B. S., Azmitia, E. C. Recovery of memory following amnesia in the rat and mouse. Journal of Comparative and Physiological Psychology, 1972, 79, 360-370.

(Received for publication July 18, 1974;

revision received August 27, 1974.) 